\title{
Anti-RhD antibody therapy modulates human natural killer cell function
}

\section{Shlomo Elias,,${ }^{1,2 *}$ Inbal Kol, ${ }^{1 *}$ Shira Kahlon, ${ }^{1}$ Rajaa Amore, ${ }^{3}$ Mariam Zeibak, ${ }^{3}$ Dror Mevorach, ${ }^{3}$ Uriel Elchalal, ${ }^{4}$ Orly Zelig ${ }^{2}$ and Ofer Mandelboim ${ }^{1}$}

${ }^{1}$ The Concern Foundation Laboratories at the Lautenberg Center for Immunology and Cancer Research, Institute for Medical Research Israel Canada (IMRIC); ${ }^{2}$ Department of Hematology; ${ }^{3}$ Rheumatology Research Center, Department of Medicine and ${ }^{4}$ Department of Obstetrics and Gynecology, Hadassah - Hebrew University Medical Center, Jerusalem, Israel.

Haematologica 2021

Volume 106(7):1846-1856

\section{Correspondence:}

OFER MANDELBOIM

oferm@ekmd.huji.ac.il

Received: September 13, 2019.

Accepted: May 27, 2020.

Pre-published: May 28, 2020.

https://doi.org/10.3324/haematol.2019.238097

\section{(C)2021 Ferrata Storti Foundation}

Material published in Haematologica is covered by copyright. All rights are reserved to the Ferrata Storti Foundation. Use of published material is allowed under the following terms and conditions:

https://creativecommons.org/licenses/by-nc/4.0/legalcode. Copies of published material are allowed for personal or internal use. Sharing published material for non-commercial purposes is subject to the following conditions:

https://creativecommons.org/licenses/by-nc/4.0/legalcode, sect. 3. Reproducing and sharing published material for commercial purposes is not allowed without permission in writing from the publisher.
* SE and IK contributed equally as co-first authors.

\section{ABSTRACT}

A nti-RhD antibodies are widely used in clinical practice to prevent immunization against $\mathrm{RhD}$, principally in hemolytic disease of the fetus and newborn. Intriguingly, this disease is induced by production of the very same antibodies when an $\mathrm{RhD}$ negative woman is pregnant with an $\mathrm{RhD}$ positive fetus. Despite over five decades of use, the mechanism of this treatment is, surprisingly, still unclear. Here we show that anti-RhD antibodies induce human natural killer (NK) cell degranulation. Mechanistically, we demonstrate that NK cell degranulation is mediated by binding of the Fc segment of anti-RhD antibodies to CD16, the main Fcy receptor expressed on NK cells. We found that this CD16 activation is dependent upon glycosylation of the anti-RhD antibodies. Furthermore, we show that anti-RhD antibodies induce NK cell degranulation in vivo in patients who receive this treatment prophylactically. Finally, we demonstrate that the anti-RhD drug KamRho enhances the killing of dendritic cells. We suggest that this killing leads to reduced activation of adaptive immunity and may therefore affect the production of anti-RhD antibodies

\section{Introduction}

Anti-RhD immunoglobulins are polyclonal antibodies which are commonly used in clinical practice. These antibodies are produced from human sera, and are mainly administered to prevent endogenous production of anti-RhD antibodies in case of exposure to the $\mathrm{RhD}$ antigen. ${ }^{1}$ This prophylactic treatment is commonly used in $\mathrm{RhD}$. women pregnant with an $\mathrm{RhD}^{+}$fetus. As such, they are at risk of developing anti$\mathrm{RhD}$ antibodies which can cause hemolytic disease of the fetus and newborn (HDFN). Paradoxically, anti-RhD antibodies are also used as prophylactic treatment for this condition. Anti-RhD antibodies are administered not only as a preventive therapy, but can also be used for treating immune thrombocytopenic purpura, ${ }^{2}$ an autoimmune disease characterized by peripheral destruction of platelets.

Despite over five decades of use, the mechanism behind anti-RhD's effect remains unclear. ${ }^{3}$ Several hypotheses have been raised to explain the clinical impact of these antibodies, but none has been definetely proven. ${ }^{1.5}$ One of the leading notions is that anti- $\mathrm{RhD}$ antibodies can cause antibody-mediated immune suppression (AMIS), even though a mechanism to explain this has not been established yet. One of the possibilities to explain AMIS is that anti-RhD antibodies lead to macrophage-mediated destruction of $\mathrm{RhD}^{+}$erythrocytes. ${ }^{6} \mathrm{~A}$ second theory hypothesizes that the anti$\mathrm{RhD}$ antibodies mask the $\mathrm{RhD}$ antigen on erythrocytes. Such masking could prevent the $\mathrm{RhD}$ antigen from being recognized by the immune system. It is estimated, however, that most of the $\mathrm{RhD}$ antigen sites remain unbound by the anti- $\mathrm{RhD}$ antibodies, and therefore should generate an immune response. ${ }^{4}$ Additional reported effects of these preparations include an increase of the cytokines transforming growth factor- $\beta$ (TGF- $\beta$ ) and prostaglandin E2. It has also been suggested that anti-RhD antibodies might cross-link the B-cell receptor and the inhibitory fragment crystallizable receptor 
(FcR) CD32B (FcyRIIb). ${ }^{4}$ However, Fcy receptors have not been shown to play a role in AMIS. ${ }^{8}$

Since the clinical effect of anti-RhD antibodies implies that they convey some immune suppression, we wondered whether these preparations affect immune cells other than $B$ cells.

Here we concentrate on natural killer (NK) cells, which are innate lymphoid cells that play a significant role in eliminating virus-infected and malignant cells. ${ }^{9}$ NK-cell activity is governed by a balance of signals from a vast array of activating (e.g., CD16a, FcyRIIIa) and inhibitory receptors that are activated by self or foreign ligands. NK cells can also interact with dendritic cells (DC) and are able to kill DC in peripheral tissues, but this cytotoxic effect mostly affects immature DC (iDC).$^{10}$ Notably, the killing of iDC by NK cells might attenuate adaptive immunity. ${ }^{10} \mathrm{NK}$ cells are also able to kill cells coated with antibody, a phenomenon known as antibody-dependent cellular cytotoxicity (ADCC). ADCC is mediated by the Fc fragment of antibodies which bind to CD16, the main FcR expressed on NK cells. ${ }^{11}$ Freshly isolated primary NK cells are mainly composed of a large, $\mathrm{CD} 56^{\mathrm{dim}} \mathrm{CD} 16^{+}$subpopulation (which expresses CD56 at intermediate levels and CD16 at high levels), and a much smaller, CD56 ${ }^{\text {bright }} \mathrm{CD} 16$ subpopulation (which expresses CD56 at high levels and does not express CD16). ${ }^{12}$

Here we show that anti-RhD antibodies activate NK cells via binding of their Fc segment to CD16 in a glycosylationdependent manner. We show that this activation occurs not only in vitro, but also in vivo, in patients who receive this treatment. We further show that the anti-RhD drug KamRho enhances killing of iDC by NK cells and discuss how this might lead to immune suppression.

\section{Methods}

\section{Erythrocyte extraction and staining}

We used commercial erythrocytes of defined phenotype (cat. 004310, Bio-Rad) or erythrocytes extracted from whole blood samples from healthy volunteers with a known $\mathrm{RhD}$ expression profile. For extraction of erythrocytes from whole blood samples, the samples were centrifuged and the supernatant was discarded. Erythrocytes were then washed three times with phosphate buffered saline (PBSx1). For flow cytometry analysis, erythrocytes were incubated at $37^{\circ} \mathrm{C}$ for 15 minutes with antibodies, washed and then incubated with a secondary antibody at room temperature for 30 minutes. Details of other procedures related to erythrocytes are described in the Online Supplementary Appendix.

\section{Natural killer cell purification and CD107a degranulation assay}

Primary NK cells were isolated from the peripheral blood of healthy human volunteers, and tested for purity as previously described. ${ }^{13}$ Unless stated otherwise, in all experiments we used NK cells which were activated as previously described. ${ }^{13}$

For the CD107a degranulation assay, primary NK cells were incubated with different polyclonal antibodies (described in the Online Supplementary Appendix) together with anti-CD107a and anti-CD56 antibodies. The NK and target cells were incubated at $37^{\circ} \mathrm{C}$ and $5 \% \mathrm{CO}_{2}$ for 2 hours and analyzed by flow cytometry. In each well we used 50,000 NK cells and $0.5 \mu \mathrm{g}$ of the relevant antibody in a final volume of $100 \mu \mathrm{L}$. Degranulation of NK cells was assessed by calculating the percent of CD107a+ $\mathrm{NK}$ cells out of the total NK cells in a given well. The data was normalized to the basal percent of CD107a $\mathrm{a}^{+} \mathrm{NK}$ cells (without addition of antibodies). The assay was performed in triplicate. For the mIgG2a blocking experiment, NK cells were pre-incubated for 30 minutes on ice with $5 \mu \mathrm{g}$ per well of the mouse IgG2a isotype control.

\section{Ethics}

The collection of patient samples was approved by the Institutional Review Board of The Hadassah Medical Center and informed consent was obtained from all participants (HMO-0091-18).

\section{Human samples}

Two peripheral blood samples were collected from $\mathrm{RhD}$ women who received prophylactic anti- $\mathrm{RhD}$ treatment while hospitalized. After erythrocyte lysis, NK cell degranulation was quantified using flow cytometry as the percent of $\mathrm{CD} 107 \mathrm{a}^{+} \mathrm{CD} 56^{+}$ $\mathrm{CD}^{-}$cells out of $\mathrm{CD}^{2} 6^{+} \mathrm{CD} 3^{-}$cells. The assay was performed in triplicate.

\section{Dendritic cell purification}

Monocyte-derived DC were generated from $\mathrm{CD} 14^{+}$peripheral blood mononuclear cell (PBMC), which were isolated as described previously. ${ }^{14}$ Briefly, anti-CD14 magnetic beads were used to isolate monocytes from PBMC according to the manufacturer's instructions (Miltenyi Biotech, Auburn, CA, USA). Monocytes were placed in wells at a concentration of $1.25 \times 10^{6}$ cells $/ 1.5 \mathrm{~mL}$ culture medium.

\section{Cytotoxicity assays}

The in vitro cytotoxic activity of NK cells was assessed in 5-hour ${ }^{35} \mathrm{~S}$-release assays as previously described. ${ }^{13} \mathrm{DC}$ were incubated for 48 hours with $20 \mu \mathrm{l}$ of ${ }^{35} \mathrm{~S}$ - methionine prior to incubation with NK cells. K562, 721.221 or primary B cells were incubated for 24 hours with $4 \mu \mathrm{l}$ of ${ }^{35} \mathrm{~S}$ - methionine, in methionine-free medium prior to incubation with NK cells. NK cells were pre-incubated for 2 hours at $37^{\circ} \mathrm{C}$ with different polyclonal antibodies (described in the Online Supplementary Appendix), at a concentration of $0.5 \mu \mathrm{g}$ per well, diluted in RPMI medium. For the blocking experiment, NK cells were pre-incubated for 30 minutes on ice with $5 \mu \mathrm{g}$ mIgG2a per well.

\section{Results}

\section{Anti-RhD preparations induce natural killer cell degranulation}

In order to investigate the effect of anti-RhD antibodies on NK cells, we used two common commercial preparations of anti-RhD antibodies: Rhophylac and KamRho. Both are produced from human sera and used clinically. In order to verify that these preparations specifically bind the $\mathrm{RhD}$ antigen, we first stained erythrocytes with known $\mathrm{RhD}$ expression. As expected, $\mathrm{RhD}^{+}$erythrocytes were recognized by both anti- $\mathrm{RhD}$ products, in contrast to $\mathrm{RhD}$ erythrocytes (Figure 1A). Next, we tested whether the anti$\mathrm{RhD}$ preparations affect $\mathrm{NK}$ cell activation. We incubated activated human NK cells (which only contain CD56 dim CD $16^{+}$cells, Online Supplementary Figure S1A) with anti-RhD antibodies and used flow cytometry to assess the level of CD107a, a marker of NK cell degranulation..$^{15}$ Since anti- $\mathrm{RhD}$ preparations also contain non-specific human antibodies, we used intravenous immunoglobulin (IVIG) at the same concentration as the total antibody concentration of these preparations as a control. Neither of the IVIG products (Intratect and Kiovig) significantly affected the degranulation level of NK cells (Figure 1B). Both of the anti- $\mathrm{RhD}$ 
preparations, however, caused significant activation of NK cells, demonstrated by a substantial increase in CD107a levels (Figure 1B). Primary NK cells obtained from eight different healthy donors displayed similar effects (Figure 1C). In order to corroborate these findings, we examined the degranulation level of primary activated NK cells incubated with increasing doses of the anti-RhD preparation KamRho, and observed a dose-dependent response (Figure
1D). Similar results were obtained using the anti-RhD preparation Rhophylac (Online Supplementary Figure S1B).

\section{Natural killer cell degranulation is mediated specifically by anti-RhD antibodies}

Since both anti-RhD antibody mixtures contain mainly non-specific antibodies, we sought to investigate whether the degranulation effect is mediated specifically by anti-

A

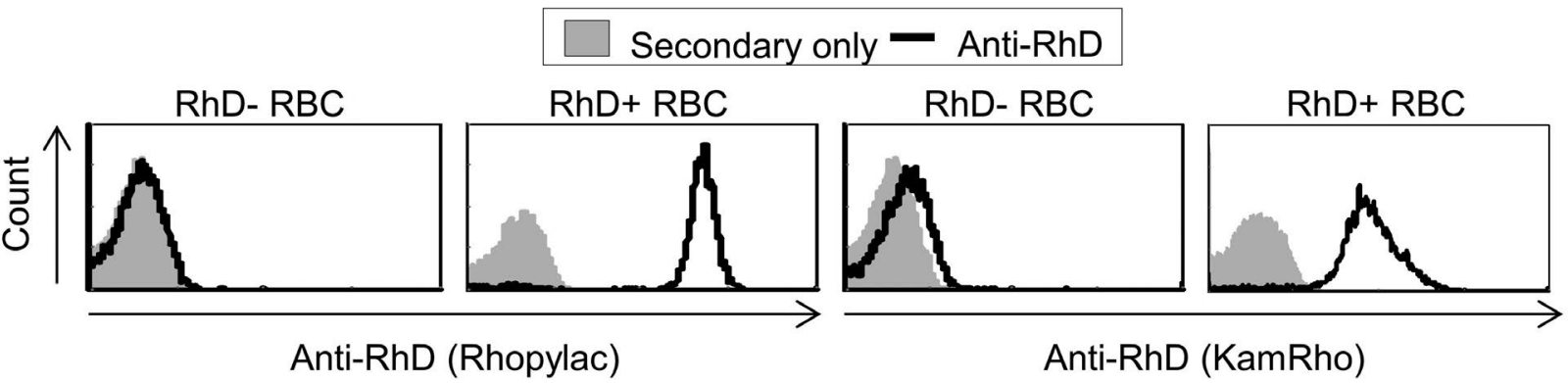

B

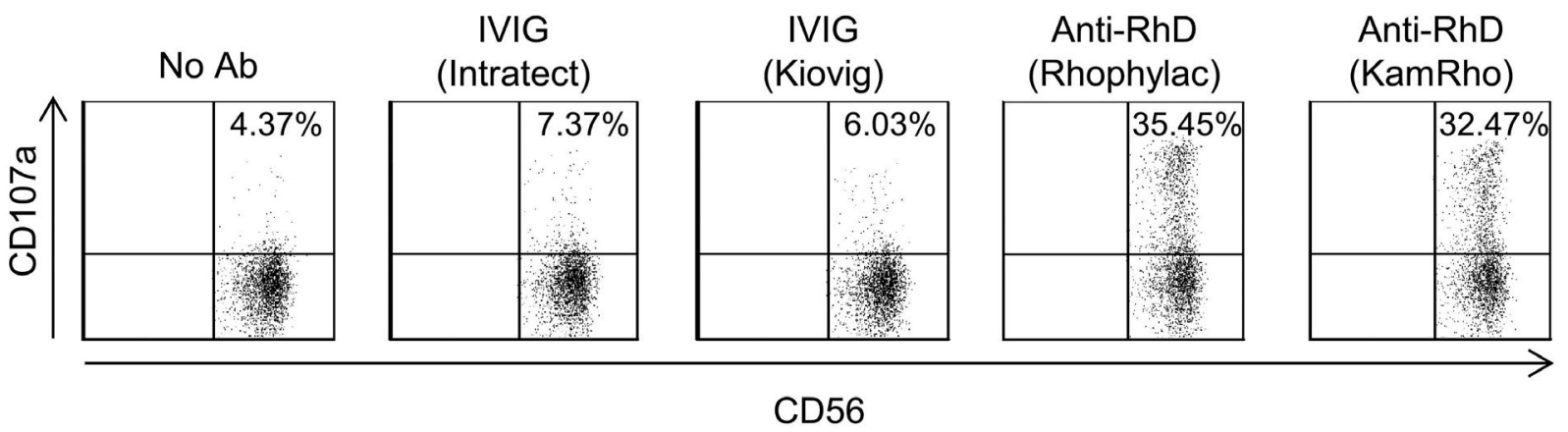

C

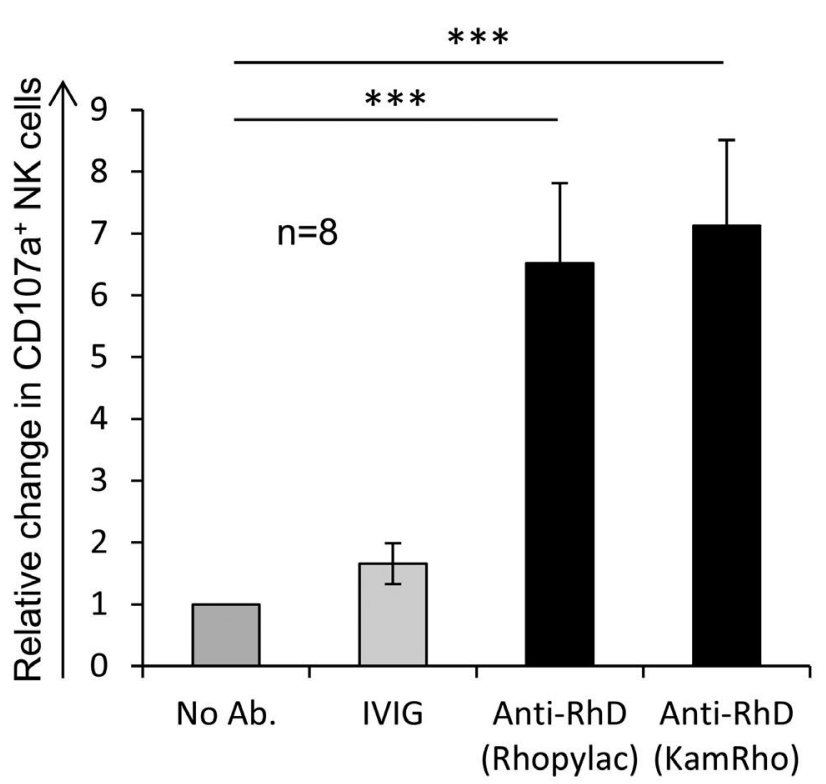

D

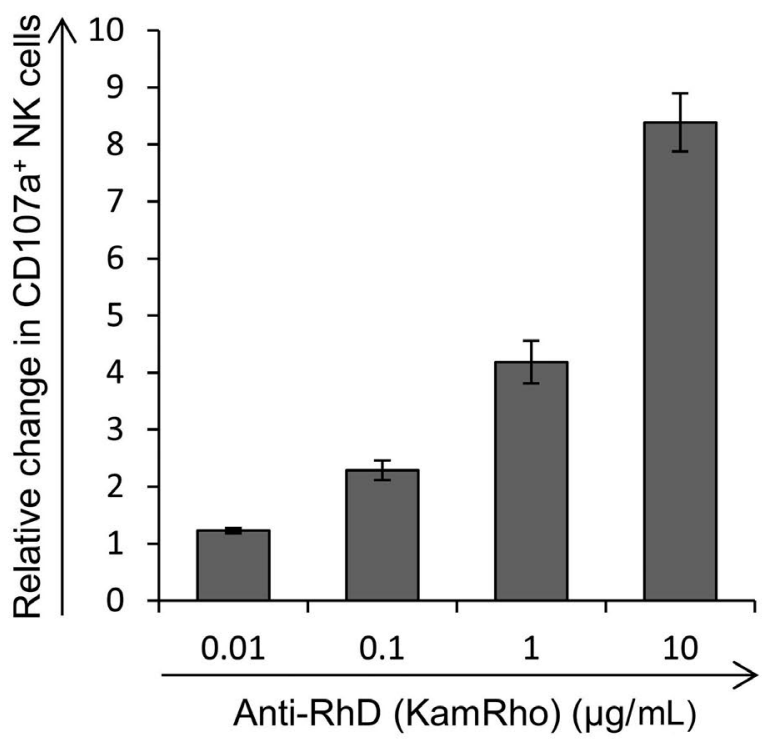

Figure 1. Anti-RhD antibodies induce degranulation of natural killer cells. (A) Staining of erythrocytes (red blood cells [RBC]) with a pre-defined RhD expression profile using two commercial anti-RhD preparations: Rhophylac (left two panels) and KamRho (right two panels). Gray filled histograms represent the background staining with the secondary antibody. One representative experiment is shown out of three performed. (B) Degranulation of natural killer (NK) cells incubated with various commercial human polyclonal antibodies. NK-cell degranulation was assessed by calculating the percentage of CD107a ${ }^{+}$NK cells out of the total NK cells (analyzed by flow cytometry). The percent of degranulated NK cells is indicated in each scatter plot. (C) The average NK-cell degranulation of eight different NK-cell donors after incubation with different polyclonal antibodies. The NK-cell degranulation level was calculated as in (B) and then normalized to the basal percent of CD107a+ NK cells without antibody (no Ab). $* * * P<0.001$; ANOVA with Tukey's HSD post-hoc test. Error bars represent standard error. (D) Degranulation of NK cells following incubation with increasing doses of KamRho. Error bars represent standard deviation of triplicates. One representative experiment is shown out of three performed. 
A

Unbound

RhD- or RhD+ RBC

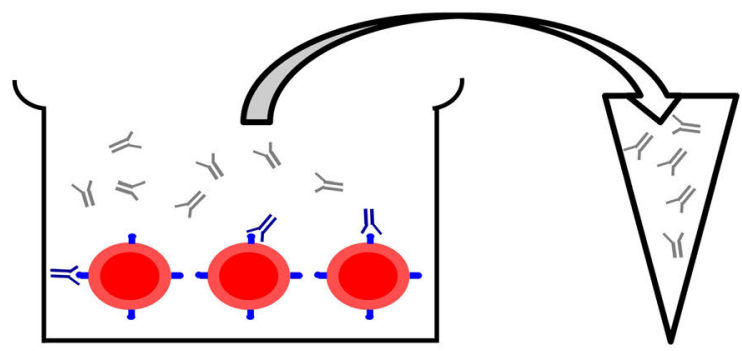

B

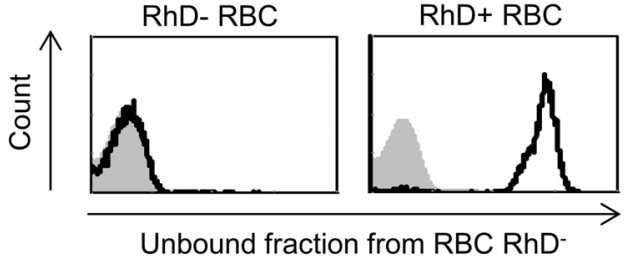

C

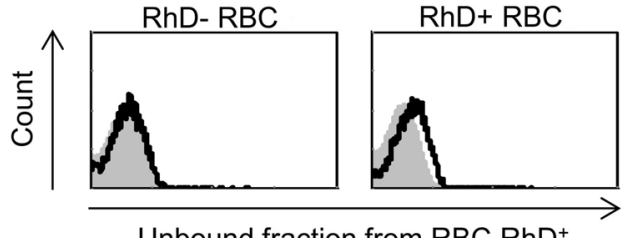

Unbound fraction from $\mathrm{RBC}^{\mathrm{RhD}}{ }^{+}$
D

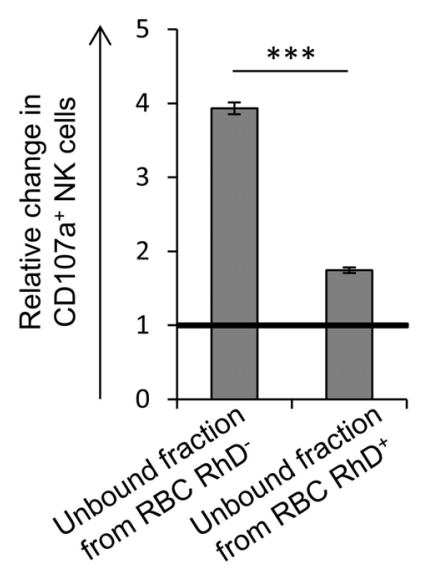

E

Bound

RhD- or RhD+ RBC

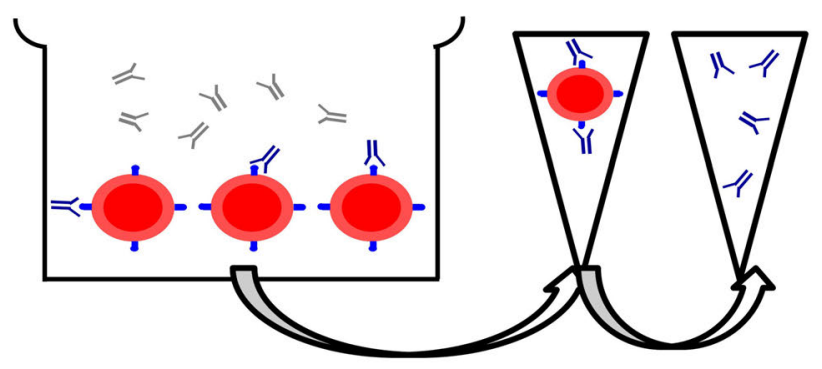

F

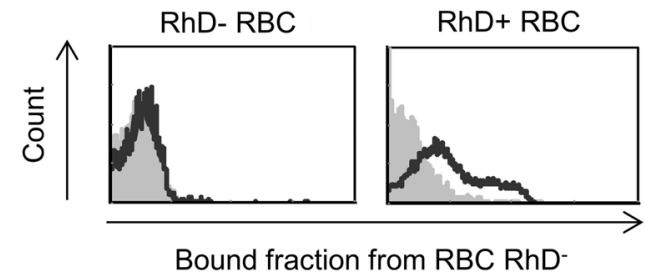

G

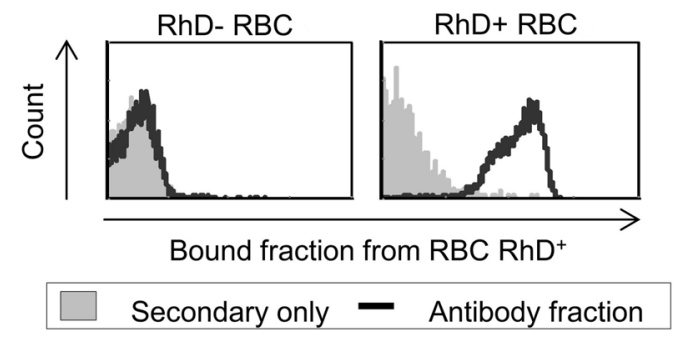

H

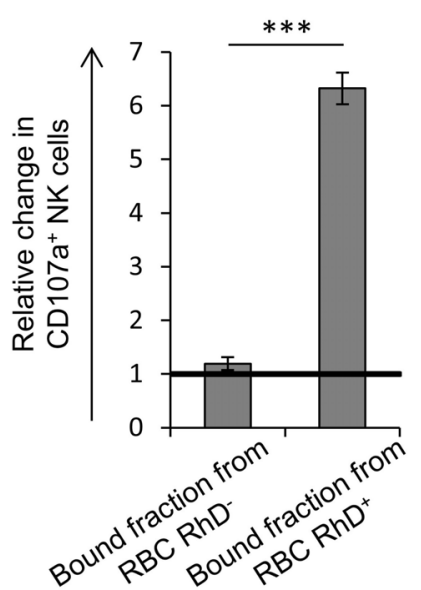

Figure 2. Specific anti-RhD antibodies mediate the degranulation of natural killer cells. (A to D) Preparation of the "unbound" antibody fractions and their effect on natural killer (NK)-cell degranulation. (A) Illustration of the production of unbound antiRhD antibodies. Anti-RhD antibodies were incubated with RhD (B) or $\mathrm{RhD}^{+}(\mathrm{C})$ erythrocytes and then the supernatant was collected and used for staining $\mathrm{RhD}^{-}$(left) and $\mathrm{RhD}^{+}$(right) erythrocytes. (D) Degranulation of NK cells incubated with the unbound antibody fractions, prepared as illustrated in (A). The NK-cell degranulation level was normalized to the basal percent of $\mathrm{CD} 107 \mathrm{a}^{+} \mathrm{NK}$ cells. ( $\mathrm{E}$ to $\mathrm{H}$ ) Preparation of the "bound" antibody fractions and their effect on NK-cell degranulation. (E) Illustration of the production of bound anti-RhD antibodies. Anti$\mathrm{RhD}$ antibodies were incubated with $\mathrm{RhD}^{-}(\mathrm{F})$ or $\mathrm{RhD}^{+}(\mathrm{G})$ erythrocytes. The eluates containing the bound antibody fractions were then extracted and used for staining $\mathrm{RhD}^{-}$(left) and $\mathrm{RhD}^{+}$ (right) erythrocytes. (H) Degranulation of NK cells incubated with the bound antibody fractions, prepared as illustrated in $(E)$, and normalized as in (D). For all experiments, one representative experiment is shown out of at least two performed. $* * * P<0.001$; Student's $t$-test. Error bars represent standard deviation of triplicates. 
A

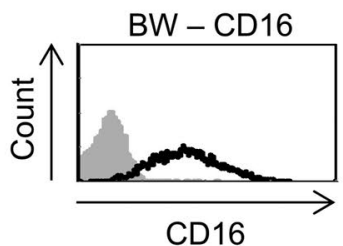

CD16

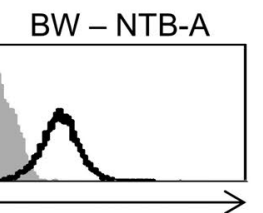

NTB-A

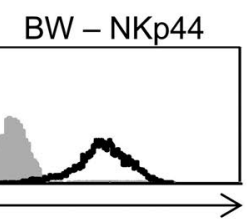

NKp44

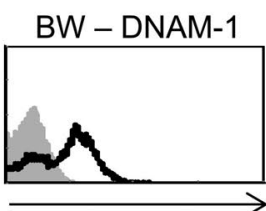

DNAM-1

Isotype control $\quad$ Specific antibody

B

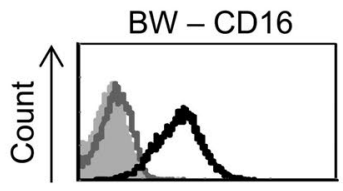

BW - NTB-A

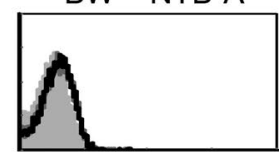

BW - NKp44

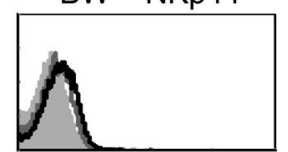

BW - DNAM-1

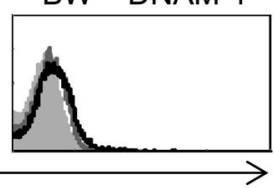

Anti-RhD (KamRho)

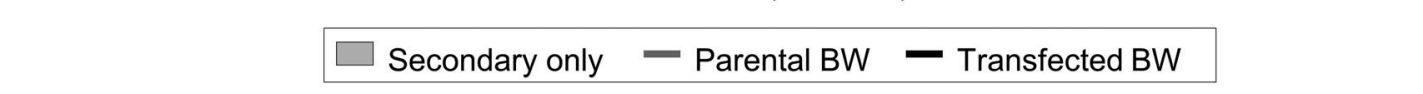

C

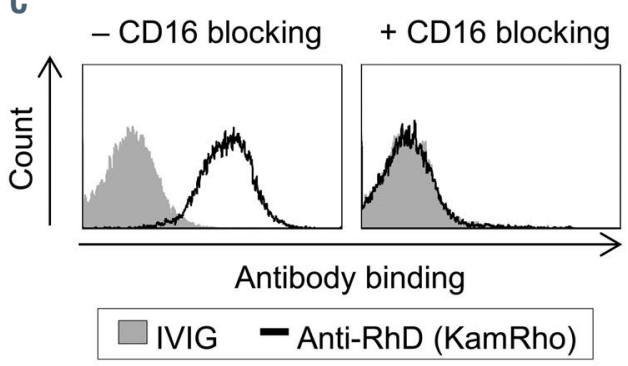

$\mathbf{F}$

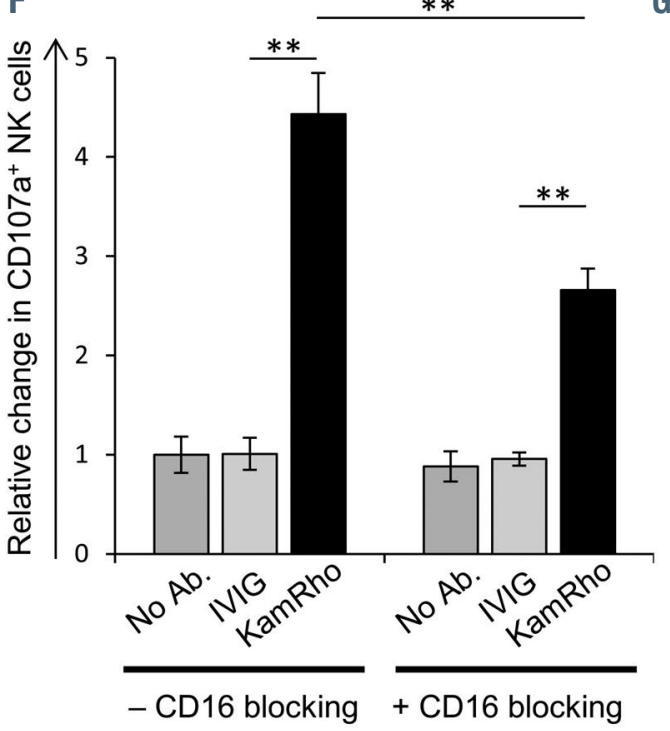

G
D

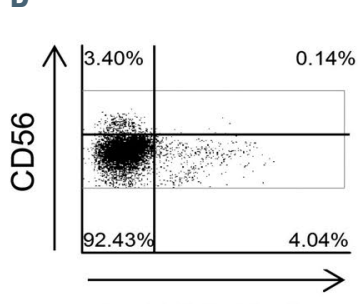

Anti-RhD binding
E

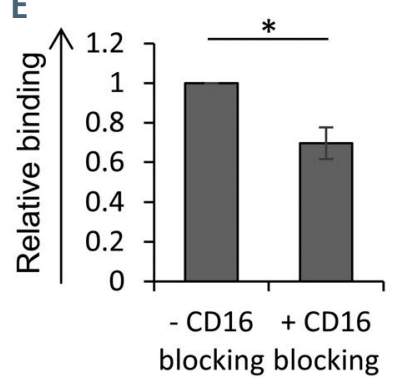

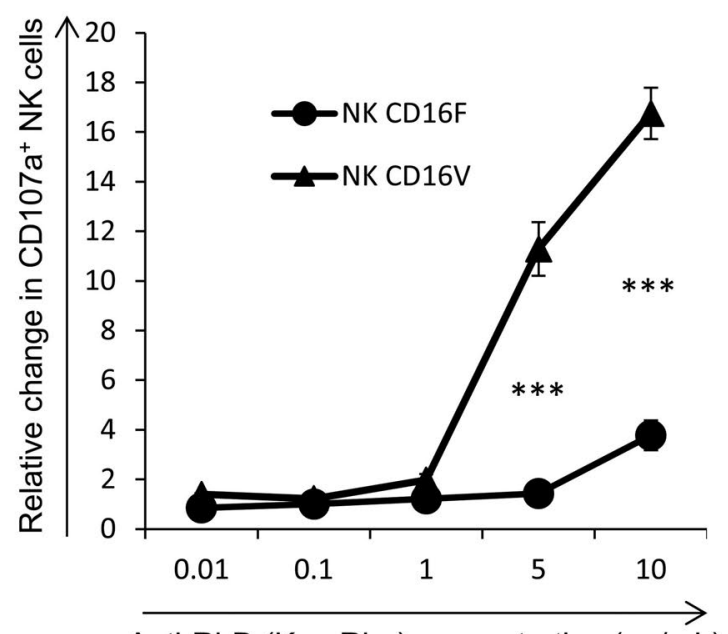

Anti-RhD (KamRho) concentration $(\mu \mathrm{g} / \mathrm{mL})$

Figure 3. Anti-RhD antibodies induce natural killer cell degranulation by binding to CD16. (A to B) Staining of transfected BW cells which express the extracellular domain of specific NK-cell receptors. The receptor expressed by each BW cell line is indicated above each histogram. (A) Staining with different antibodies as indicated below each histogram, in order to verify receptor expression; gray filled histograms represent staining with isotype control antibodies. (B) Staining with KamRho; gray filled histograms represent staining with secondary antibody and gray histograms represent staining of the parental BW cells. (C) Staining of BW-CD16 cells with intravenous immunoglobulin (IVIG) (gray filled histograms) or KamRho (black histograms), without (left panel) or with (right panel) blocking of CD16 by mouse IgG2a. (D) Staining of freshly isolated NK cells with the bound RhD+ fraction. Gating was on the CD56+ cell population (gray box). The $y$-axis presents the CD56 expression level; cells above the black line are CD56 bight $(C D 16)$ and those below it are CD56 dim $\left(C D 16^{+}\right)$. (E) Staining of bulk activated NK cells with the bound RhD fraction, with or without blocking of CD16 by mouse IgG2a. Gating was on all living NK cells. The figure shows the average of three experiments, performed on NK cells from three different donors. For each donor, the percent of stained NK cells in both conditions was normalized to the percent of stained NK cells without blocking. $\star P<0.05$; paired student's $t$-test. Error bars represent standard deviation. (F) Degranulation of NK cells incubated with KamRho or IVIG, with or without blocking of CD16 by mouse IgG2a. The NK-cell degranulation level was normalized to the basal percentage of CD107a ${ }^{+}$NK cells without antibody (no Ab.). ** $P<0.01$; Student's $t$-test. Error bars represent standard deviation of triplicates. (G) Primary NK cells were isolated from donors who express the low- (158F) or high-affinity (158V) variants of CD16. These NK cells were incubated with increasing doses of KamRho and then the NK-cell degranulation was assessed. The NK-cell degranulation level was normalized to the basal percent of $\mathrm{CD} 107 \mathrm{a}^{+} \mathrm{NK}$ cells. One representative experiment is shown out of two performed. $* * * P<0.001$; Student's $t$-test. Error bars represent standard deviation of triplicates. 
$\mathrm{RhD}$ antibodies. In order to address this, we incubated KamRho with $\mathrm{RhD}^{+}$erythrocytes and collected the supernatant, which consists of antibodies that did not bind to erythrocytes ("unbound" fraction, Figure 2A). As a control, we performed the same adsorption process with $\mathrm{RhD}$ erythrocytes, which are not expected to adsorb $\mathrm{RhD}$-specific antibodies (Figure 1A). We first confirmed the efficiency of the process by staining $\mathrm{RhD}^{-}$and $\mathrm{RhD}^{+}$erythrocytes with the two unbound antibody fractions. As expected, the unbound fraction from $\mathrm{RhD}$ erythrocytes did not stain $\mathrm{RhD}$ erythrocytes (Figure $2 \mathrm{~B}$, left panel), but did stain $\mathrm{RhD}^{+}$ erythrocytes (Figure $2 \mathrm{~B}$, right panel). In contrast, the unbound fraction from $\mathrm{RhD}^{+}$erythrocytes no longer stained erythrocytes regardless of their $\mathrm{RhD}$ status (Figure 2C), thus demonstrating the efficiency of the adsorption process.

We next examined the effect of the unbound fraction on NK-cell degranulation. We found that the unbound fraction from RhD erythrocytes highly activated NK cells, in contrast to the unbound fraction from $\mathrm{RhD}^{+}$(Figure 2D). In order to further corroborate the potency of specific anti$\mathrm{RhD}$ antibodies in inducing NK-cell degranulation, we eluted the specific anti-RhD antibodies bound to $\mathrm{RhD}^{+}$erythrocytes ("bound" fraction, Figure 2E). As a control, we performed the same elution process with $\mathrm{RhD}$ erythrocytes. We verified the elution process by staining $\mathrm{RhD}^{-}$and $\mathrm{RhD}^{+}$ erythrocytes with these bound fractions (Figure $2 \mathrm{~F}$ to $\mathrm{G}$ ). Similar to the original antibody preparation, neither bound fraction stained $\mathrm{RhD}$ erythrocytes (Figure $2 \mathrm{~F}$ to $\mathrm{G}$, left panels). While the bound fraction from $\mathrm{RhD}$ erythrocytes minimally stained $\mathrm{RhD}^{+}$erythrocytes, the bound fraction from $\mathrm{RhD}^{+}$erythrocytes, as expected, significantly stained $\mathrm{RhD}^{+}$ erythrocytes (Figure $2 \mathrm{~F}$ to $\mathrm{G}$, right panels). Both bound fractions were then incubated with NK cells and we determined degranulation levels as before (Figure $2 \mathrm{H}$ ). The bound fraction from $\mathrm{RhD}^{+}$erythrocytes induced significant NK cell degranulation as compared to the bound fraction from $\mathrm{RhD}$ erythrocytes (Figure $2 \mathrm{H}$ ). Based on these results we concluded that it is the specific anti-RhD antibodies which induce NK-cell degranulation.

\section{Anti-RhD antibodies induce natural killer cell degranulation by binding to CD16}

We next explored how anti-RhD antibodies induce NKcell degranulation. Because NK cells do not express the RhD antigen, ${ }^{16}$ we focused on CD16, the main FcR expressed by NK cells, as we suspected it binds the Fc portion of the anti$\mathrm{RhD}$ antibodies. In order to test this possibility, we stained several transfected BW cells which express the extracellular domain of CD16 or of a control NK-cell receptor (NTB-A, NKp44 or DNAM-1). We first verified that each of the transfected BW cells expresses the extracellular domain of the given receptor (Figure $3 \mathrm{~A}$ ). We then stained these transfected BW cells with KamRho and analyzed the cells by flow cytometry (Figure 3B). We found that KamRho binds to CD16, but not to other tested NK-cell receptors (Figure 3B). Similar results were obtained with Rhophylac (Online Supplementary Figure S1C). Pre-blocking of CD16 with mouse IgG2a isotype, known to bind CD16 with high affinity ${ }_{17}^{17}$ abolished the binding of KamRho to BW-CD16, as compared with IVIG binding (Figure 3C).

In order to further explore the possibility that anti-RhD antibodies bind CD16, we double-stained primary freshly isolated $\mathrm{NK}$ cells using the bound $\mathrm{RhD}^{+}$fraction we generated (shown in Figure 2 E, G to H), and an anti-CD56 anti- body. In concordance with our expectations, we observed binding of the anti-RhD antibodies to CD56 ${ }^{\mathrm{dim}} \mathrm{NK}$ cells that express CD16, but not to $\mathrm{CD} 56^{\text {bright }} \mathrm{CD} 16$ negative NK cells (Figure 3D). The relatively low binding to CD56 ${ }^{\mathrm{dim}} \mathrm{NK}$ cells is probably due to limitations of staining human NK cells with human antibodies, as discussed below. Furthermore, blocking of CD16 on activated NK cells significantly reduced the binding of the bound $\mathrm{RhD}^{+}$fraction to activated NK cells (Figure 3E).

In order to corroborate these results, we repeated the staining of freshly isolated NK cells with a fluorochromeconjugated KamRho which we generated. This staining clearly demonstrated a specific binding to CD56 ${ }^{\mathrm{dim}}\left(\mathrm{CD} 16^{+}\right)$ NK cells (Online Supplementary Figure S2). Taken together, these findings indicate that anti-RhD antibodies bind CD16 on NK cells.

Next, in order to determine whether anti-RhD - CD16 interaction is responsible for the NK-cell degranulation, we repeated the degranulation assay with pre-blocking of CD16 on NK cells. Pre-blocking significantly reduced the degranulation levels induced by anti-RhD antibodies (KamRho in Figure 3F and Rhophylac in the Online Supplementary Figure S3A).

In order to further elucidate the role of CD16 in anti-
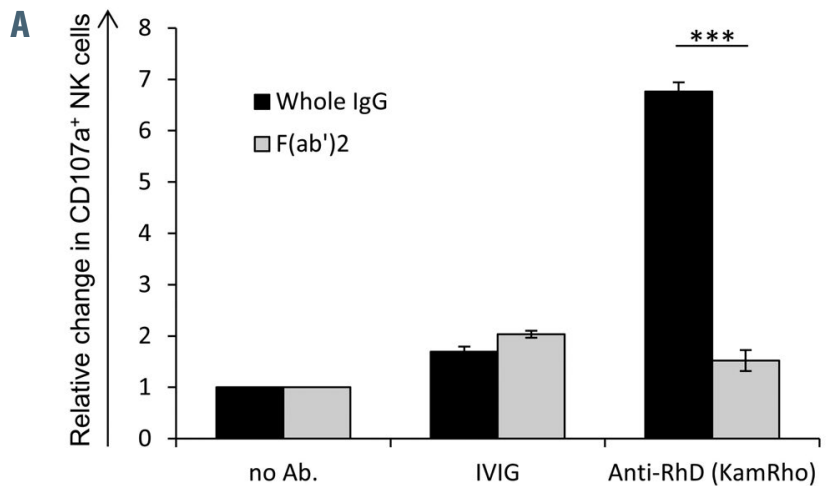

B

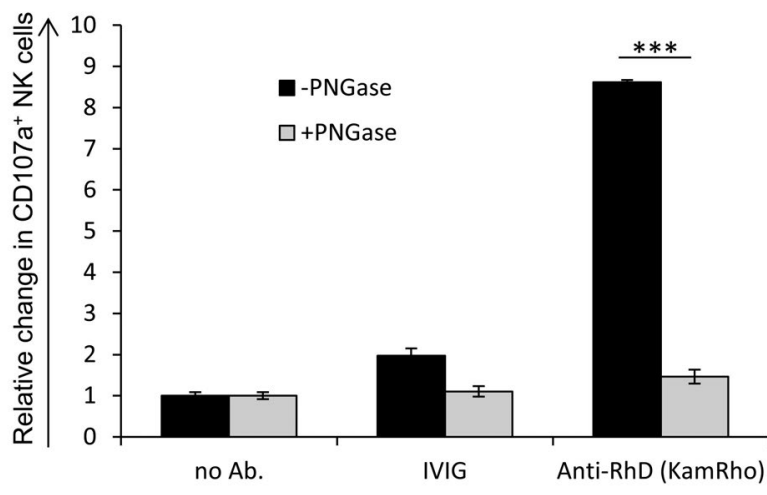

Figure 4. Anti-RhD antibodies induce degranulation of natural killer cells through their Fc segment. (A to B) Natural killer (NK)-cell degranulation assays. (A) $F\left(a b^{\prime}\right)_{2}$ fragments were produced from KamRho antibodies. NK cells were incubated with equal concentrations of the $F\left(a b^{\prime}\right)_{2}$ fragments or whole KamRho and intravenous immunoglobulin (IVIG). The NK-cell degranulation level was normalized to the basal percent of CD107a ${ }^{+}$NK cells without antibody (no Ab.). (B) KamRho and IVIG were deglycosylated with PNGase under non-denaturing conditions. NK cells were incubated with equal concentrations of the deglycosylated or the original antibodies. The NK-cell degranulation level was normalized to the basal percent of $\mathrm{CD} 107 \mathrm{a}^{+} \mathrm{NK}$ cells without antibody (no Ab.) $* * * P<0.001$; Student's $t$-test. Error bars represent standard deviation of triplicates. 
$\mathrm{RhD}$-induced NK-cell degranulation, we cultured primary NK cells from donors who are homozygous for either of the low- or high-affinity alleles of CD16 (158F and 158V respectively) ${ }^{18}$ We performed degranulation assays with both NK cells in parallel, which were incubated with KamRho (Figure 3G) or Rhophylac (Online Supplementary Figure S3B). We found significant differences in the extent of NK-cell degranulation between the donors (Figure 3G; Online Supplementary Figure S3B). We therefore concluded that anti-RhD antibodies induce degranulation of $\mathrm{NK}$ cells by binding to CD16.

\section{Fc glycosylations of anti-RhD antibodies are essential for inducing natural killer cell degranulation}

As CD16 is an FcR, we wished to confirm that anti-RhD antibodies mediate their effect via their Fc segments. Therefore, we performed a degranulation assay with NK cells incubated with anti-RhD antibodies or $\mathrm{F}\left(\mathrm{ab}^{\prime}\right)_{2}$ derivatives produced from KamRho and Rhophylac. As a control we used IVIG and $\mathrm{F}\left(\mathrm{ab} \mathrm{b}^{\prime}\right)_{2}$ fragments of IVIG. In contrast to the degranulation induced by the whole anti- $\mathrm{RhD}$ antibodies, the $F\left(a b^{\prime}\right) 2$ segments did not induce degranulation of NK cells (Figure 4A; Online Supplementary Figure S3C). This indicates that the Fc segment of anti-RhD antibodies is necessary for CD16-induced NK-cell degranulation.

In order to understand why the Fc fragments of anti-RhD antibodies, but not those of IVIG, activate NK cells, we investigated which element of the Fc is important for this effect. Since the human IgG subclasses 1, 2, 3, and 4 differ in their immune properties, ${ }^{19}$ we initially quantified the abundance of these subclasses in KamRho and Rhophylac, as well as in IVIG. Although some differences could be observed, we did not detect significant enrichment of a specific IgG subclass in the anti- $\mathrm{RhD}$ preparations as compared to IVIG (Online Supplementary Table S1), indicating that the functional difference is not due to a specific $\operatorname{IgG}$ subclass.

As Fc glycosylations have a critical influence on antibody function, ${ }^{20,21}$ we next examined the role of Fc glycosylations on anti-RhD-mediated NK-cell degranulation. We treated KamRho and Rhophylac with peptide:N-glycosidase F (PNGase F), an enzyme which cleaves N-linked oligosaccharides, and repeated the degranulation assay with the treated antibodies. Removal of glycosylations from KamRho and Rhophylac abolished their ability to induce degranulation of NK cells (Figure 4B; Online Supplementary Figure S3D, respectively), indicating that anti-RhD antibodies activate NK cells via glycosylation-dependent binding of their Fc segment to CD16.

\section{Treatment with anti-RhD antibodies increases natural killer cell degranulation in humans}

Since anti-RhD preparations are widely used in clinical settings we wished to determine whether anti-RhD antibodies affect NK-cell degranulation in humans. We therefore collected peripheral blood samples from pregnant women who received prophylactic treatment with anti$\mathrm{RhD}$. We collected two samples from each woman: the first sample was obtained just before administration of the anti-RhD injection, and the second sample was obtained 3 hours post-injection. Samples were stained and analyzed for CD107a levels by flow cytometry with gating on NK cells $\left(\mathrm{CD}^{2} 6^{+} \mathrm{CD}^{-}\right)$. Two NK-cell populations were observed and referred to as PBL1 and PBL2 (Figure 5A and B). We initially gated on the PBL2 population, which were
A
B

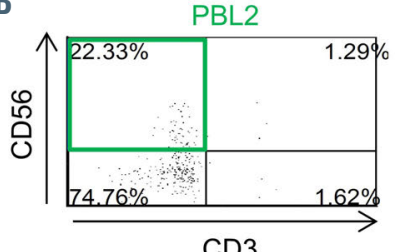

CD3

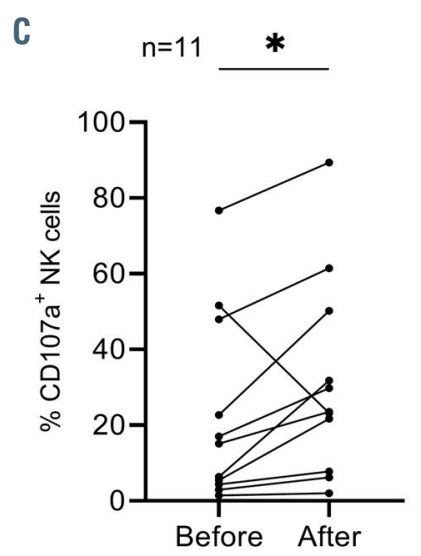

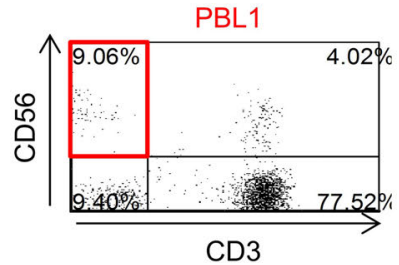

CD3

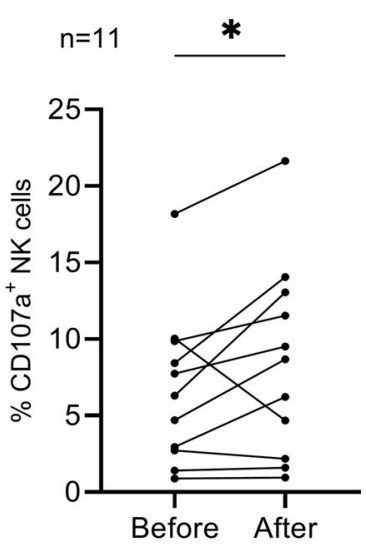

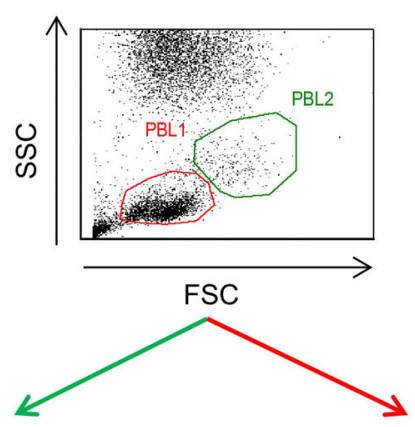

Figure 5. Treatment with anti-RhD antibodies increases natural killer cell degranulation in humans. (A-B) Gating strategy for assessment of natural killer (NK)-cell degranulation in human patients. Human peripheral blood (PB) samples were stained and analyzed by flow cytometry. (A) Size-based gating of two populations of cells (PBL1 and PBL2). (B) NK cells were identified as CD3-CD56 ${ }^{+}$cells, after size-based gating. (C) Summary of the effect of anti-RhD treatment on NK cell degranulation in 11 women. NK-cell populations PBL2 (left panel) and PBL1 (right panel) were stained for CD107a. For each sample (before and after), NK-cell degranulation was assessed by calculating the percentage of CD107a+ $\mathrm{NK}^{+}$cells out of the total NK cells. The triplicate average for each condition (before/after) of each patient was then plotted and used for the statistical test. Each black line represents a single patient. ${ }^{*} P<0.05$, Wilcoxon signed-ranks test.

larger in size and had high baseline degranulation levels, presumably representing activated NK cells. In accordance with the in vitro degranulation assays, we noted a significant increase in the degranulation levels in almost all patients (10 of 11) with an average 2.06-fold increase in NK-cell degranulation after receiving anti-RhD (Figure 5C, left panel). Similar results were observed when gating on the PBL1 NK population (Figure $5 \mathrm{~A}$ to $\mathrm{C}$, right panels), with an average 1.34-fold increase in NK-cell degranulation after anti-RhD treatment (Figure 5C, right panel).

\section{The anti-RhD drug KamRho induces killing of immature and mature dendritic cells by natural killer cells}

Finally, we explored the possibility that anti-RhD-induced activation of NK cells helps to prevent production of anti$\mathrm{RhD}$ antibodies by B cells, the desired clinical outcome of this treatment. As NK cells can kill iDC in peripheral tissues, 

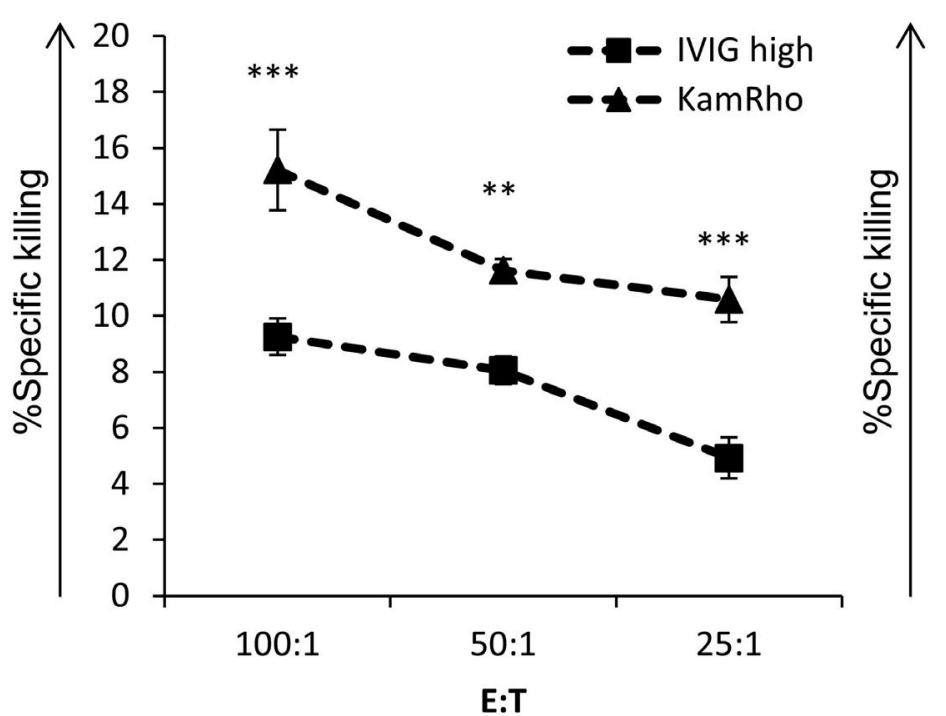

C

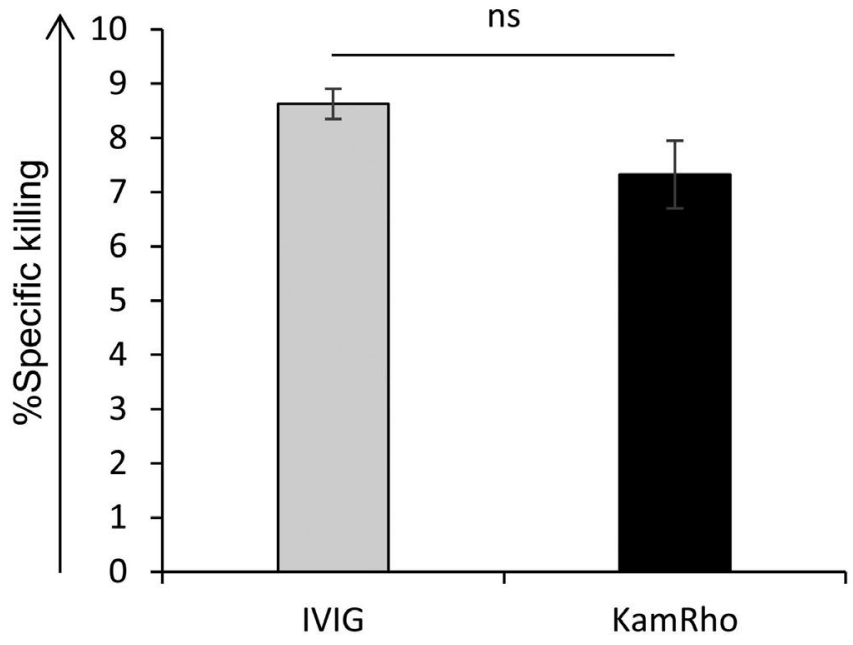

Figure 6. The anti-RhD drug KamRho induces killing of immature dendritic cells by natural killer cells. (A) Cytotoxicity assay. ${ }^{35}$ S-labeled immature dendritic cells (iDC) were incubated with activated natural killer (NK) cells and different polyclonal antibodies (intravenous immunoglobulin [IVIG] or KamRho). The effector to target (E:T) ratio is indicated on the $x$-axis. One representative experiment is shown out of five performed. $* * P<0.01, * * * P<0.001$; ANOVA with Tukey's HSD post-hoc test. Error bars represent standard deviation of triplicates. (B) Cytotoxicity assay was performed as in (A), with ${ }^{35}$ S-labeled mature DC $(\mathrm{mDC})$ cells used as targets. One representative experiment is shown out of two performed. $* P<0.05, * * P<0.01$; $* * * P<0.001$; ANOVA with Tukey's HSD post-hoc test. Error bars represent standard deviation of triplicates. (C) Cytotoxicity assay was performed as in (A), with ${ }^{35} \mathrm{~S}$ labeled IDC cells as targets, at an E:T ratio of 50:1. The assay was performed with pre-blocking of CD16 on NK cells using mouse IgG2a. One representative experiment is shown out of two performed. ns: non-significant; Student's $t$-test. Error bars represent standard deviation of triplicates. (D) Cytotoxicity assay. B lymphocytes, 721.221 , or K562 cells were ${ }^{35} \mathrm{~S}$-labeled and then incubated with activated NK cells and different polyclonal antibodies (IVIG or KamRho). The E:T ratio is 50:1 for B lymphocytes and 5:1 for 721.221 and K562 cells. One representative experiment is shown out of five performed with 721.221 and K562 cells, and two performed with B lymphocytes. ns: non-significant; Student's $t$-test. Error bars represent the standard deviation of triplicates.

D

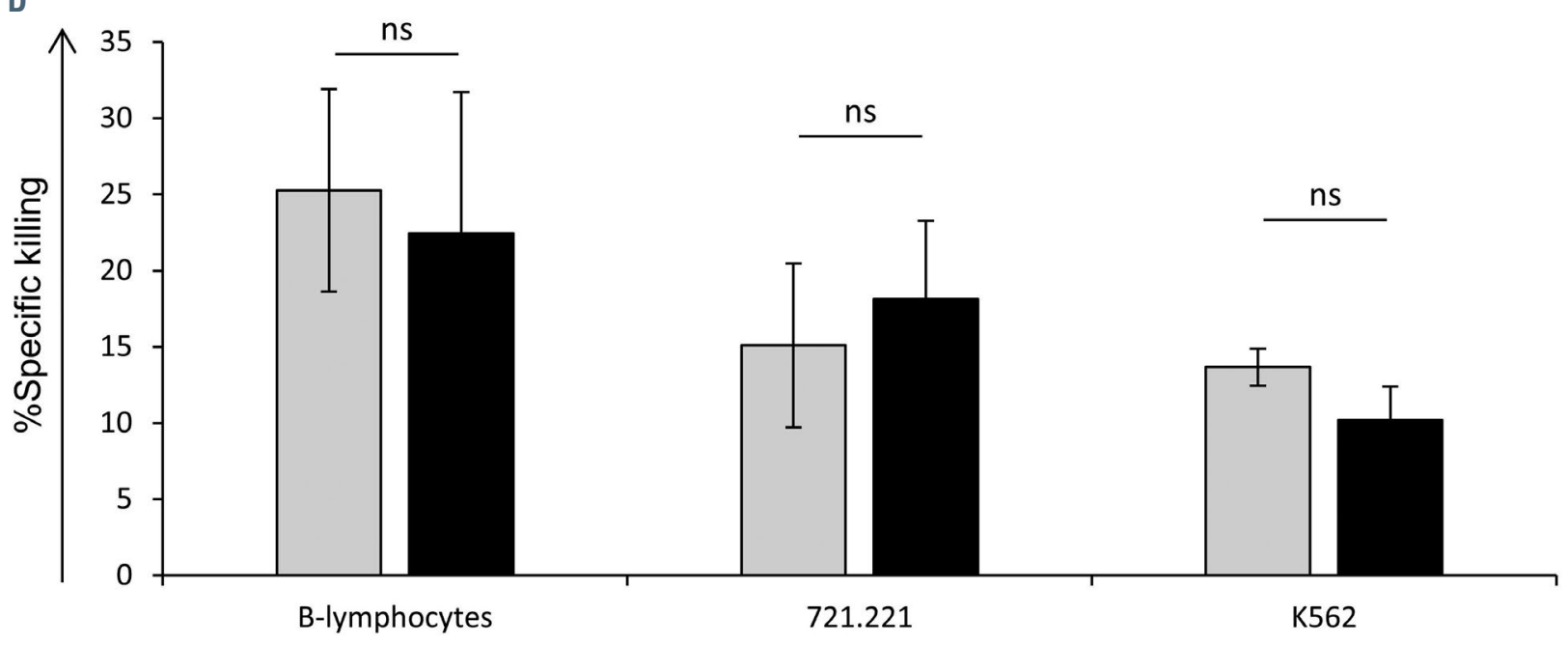

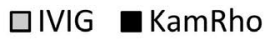


regulating adaptive immunity ${ }^{10}$, we tested whether anti$\mathrm{RhD}$ antibodies affect this process.

We performed NK cytotoxicity assays, in which we measured the killing of mature $\mathrm{DC}(\mathrm{mDC})$ activated by lipopolysaccharide (LPS) and of iDC by NK cells which were pre-incubated with KamRho, Rhophylac or IVIG. The phenotype of $\mathrm{iDC}$ and $\mathrm{mDC}$ is presented in the Online Supplementary Figure S4A. At all effector to target ratios tested, pre-incubation with KamRho increased the killing of iDC by NK cells (Figure 6A). KamRho also increased the killing of $\mathrm{mDC}$ by NK cells, although the killing levels were significantly lower (Figure 6B), which is in line with previous reports. ${ }^{22-24}$ Pre-blocking of CD16 on NK cells with mouse IgG2a abolished the differences between KamRho and IVIG (Figure 6C). Interestingly, pre-incubation of NK cells with Rhophylac did not increase the killing of neither iDC nor mDC (Online Supplementary Figure S4B and C, respectively), although both drugs were able to induce degranulation of NK cells (Figure 1C).

Because anti-RhD antibody preparations contain mainly non-specific antibodies, we next verified that the increased killing effect is specifically due to anti-RhD antibodies. We repeated the cytotoxicity assay, this time using the bound antibody fractions we eluted from $\mathrm{RhD}^{-}$and $\mathrm{RhD}^{+}$erythrocytes incubated with KamRho (as shown in Figure $2 \mathrm{E}$ to $\mathrm{H})$. As expected, the bound fraction from $\mathrm{RhD}^{+}$erythrocytes (which contains the specific anti-RhD antibodies) increased NK-cell-mediated killing of iDC significantly while the bound fraction obtained from $\mathrm{RhD}$ erythrocytes did not (Online Supplementary Figure S4D).

In order to check whether any other cells, particularly B cells, could also be more effciently killed in the presence of KamRho, we repeated the NK cytotoxicity assay with primary B cells isolated from human donors, the B-cell line 721.221 or the myeloid-derived cell line K562, and observed no effect (Figure 6D).

\section{Discussion}

Anti-RhD Antibodies are widely used in clinical practice, mainly to prevent immunization against the $\mathrm{RhD}$ antigen. Surprisingly, although prophylactic administration of anti$\mathrm{RhD}$ antibodies is a common, safe, and successful treatment (in terms of preventing HDFN), the mechanism of this therapy remains unclear. One of the common theories suggests that this treatment can cause AMIS, though there is no single definitive mechanism for this suppression.

One of the limitations of anti-RhD antibodies is that these products are manufactured from the sera of human subjects who are immunized against $\mathrm{RhD}$. In light of the success of the preventive anti-RhD therapy, the number of immunized donors has decreased significantly. In order to overcome this drawback, in recent years several recombinant monoclonal antibodies against $\mathrm{RhD}$ have been generated. ${ }^{25-27}$ Some studies have demonstrated clinical efficiency of monoclonal anti-RhD antibodies in preventing $\mathrm{RhD}$ immunization, and have displayed encouraging laboratory markers (e.g., clearance of erythrocytes or antibody-dependent cytotoxicity). ${ }^{26-28}$ Nonetheless, polyclonal $\mathrm{RhD}$ antibodies are still considered the standard of care, which emphasizes that the precise mechanism of this treatment has not yet been elucidated. Deciphering this mechanism would potentially assist in generating efficient recombinant substitutions which would replace serum-based products.
Here we explored the effect of two commercial anti-RhD antibody preparations on NK-cell activity. We showed that both products induce significant degranulation of NK cells, even in the absence of target cells, and that this is mediated specifically by anti-RhD antibodies. Importantly, we also observed an increase in NK-cell degranulation following prophylactic treatment with anti-RhD antibodies in human patients.

We demonstrated that this effect occurs via binding of the Fc segment of the antibodies to CD16 in a glycosylation-dependent manner. It is possible that anti-RhD antibodies have unique glycosylations which are critical for their interaction with NK cells. This is consistent with a study which demonstrated that anti- $\mathrm{RhD}$ antibodies isolated from the plasma of alloimmunized pregnant women are less fucosylated. ${ }^{29}$ These properties should by explored in further studies.

We demonstrated a significant binding of labeled anti$\mathrm{RhD}$ antibodies to the CD56 ${ }^{\mathrm{dim}}$, but not to the CD56 bright NK-cell population of freshly isolated NK cells. However, when we used the non-labeled anti-RhD antibodies, little staining was observed. This is probably due to limitations of staining human NK cells by unlabeled human antibodies which requires anti-human secondary antibody staining. Since NK cells are coated with human immunoglobulins, ${ }^{30,31}$ the non-specific background staining with secondary antihuman antibodies is high, seemingly masking any specific binding.

We also demonstrated the role of CD16 in the anti-RhD -mediated NK-cell degranulation in other experiments (e.g., degranulation with blocking of CD16 and with low and high-affinity CD16a-expressing donors). Blocking of CD16 abolished anti-RhD-mediated degranulation significantly, yet not completely. This incomplete blocking could result from inefficiency of the blocking or might indicate that additional NK-cell receptors are involved (even though we have not observed binding of anti-RhD antibodies to several other NK-cell receptors).

We next found that the anti-RhD drug KamRho increases killing of iDC. KamRho also increased killing of $\mathrm{mDC}$, but to a lesser extent. This is in line with previous reports of the sensitivity of $\mathrm{iDC}$ as compared to $\mathrm{mDC}$ to killing by $\mathrm{NK}$ cells, which is attributed to the increased levels of major histocompatibility complex (MHC) on $\mathrm{mDC} .^{22-24}$.

Surprisingly, although the drugs Rhophylac and KamRho had similar effects in most in vitro assays performed, Rhophylac did not increase NK killing of DC. One possibility is that this difference is related to the presence of a different stabilizer in each of these drugs: albumin in Rhopylac and glycine in KamRho (glycine is also used as stabilizer in the IVIG regent we used as a control).

Interestingly, increased NK-cell activation mediated by KamRho did not enhance killing of other cell types, including $B$ cells. The reasons behind this observation are not completely understood. One possible explanation is that MHC class I proteins are involved. This option seems unlikely as K562 and 721.221 cells express little or no MHC class I, while primary B cells, iDC and to a greater extent $\mathrm{mDC}$ express high levels of MHC class I. Alternatively, it is possible that anti-RhD antibodies not only bind $\mathrm{NK}$ but can also bind DC through their Fab segment, therefore inducing ADCC. This possibility seems unlikely as the $\mathrm{RhD}$ antigen is expressed only on erythrocytes ${ }^{16}$. A final explanation might be that CD16 binds an unknown cellular ligand expressed on DC. Such a cellular ligand was previously 
reported to be expressed on 1106 mel cells. ${ }^{32}$ Further studies are required to decipher this differential killing by NK cells.

A possible mechanism arising from our work is that anti$\mathrm{RhD}$ antibodies increase NK-cell activation, resulting in increased killing of iDC. This may, in turn, lead to decreased antigen presentation and a decreased humoral response. In the context of an $\mathrm{RhD}^{-}$individual exposed to $\mathrm{RhD}^{+}$erythrocytes, this effect could diminish the production of anti-RhD antibodies, which is the clinical outcome observed upon anti-RhD prophylactic treatment. Previous studies have demonstrated that impaired killing of DC by cytotoxic T lymphocytes and NK cells can lead to continuous antigen presentation and exaggerated immune activation, ${ }^{33,34}$ as seen in hemophagocytic lymphohistiocytosis. ${ }^{35}$ We can therefore speculate that in the inverse case, activation of $\mathrm{NK}$ by anti-RhD antibodies can contribute to AMIS via killing of $\mathrm{DC}$. If administration of the anti-RhD antibodies indeed leads to the killing of DC, a general immune suppression would be expected in these women. This should be investigated in the future in a clinical study.

Although the mechanism we describe here is unrelated to ADCC of erythrocytes (anti-RhD-mediated lysis of erythrocytes by CD16 on NK cells), ADCC, if significant, could potentially also contribute to the mechanism of action of anti-RhD antibodies. Several studies have shown that NK cells are capable of lysing erythrocytes via ADCC (mainly in the context of Plasmodium falciparum infected ery-

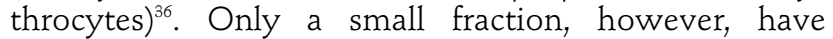
researched this effect with human allo-antibodies, let alone anti-RhD. Furthermore, these studies rarely employ direct, reliable measurements of erythrocyte lysis. ${ }^{37}$ Therefore, this important question should be comprehensively addressed by future studies.
In summary, we provide new insights into the activity of polyclonal anti-RhD antibodies which are in clinical use. These findings could contribute to the clinical efficiency of these preparations or imply that these antibodies carry unique features meriting further study.

\section{Disclosures}

No conflicts of interest to disclose.

\section{Contributions}

$S E$ and IK designed and performed experiments, analyzed results, and wrote the paper; SK performed experiments; OZ provided reagents and contributed professional advice; $R A, M Z$ and $D M$ assisted in the dendrtic cell experiments; UE was responsible for the human samples and OM supervised the project.

\section{Acknowledgments}

The authors thank Yulia Gendler and Dr. Shulamit Metsger from the Hadassah Blood Bank (Jerusalem, Israel) for their fruitful discussions and assistance with the erythrocyte experiments, Suhair Abdeen from Hadassah Medical Center (Jerusalem, Israel) for the isotype analysis and Natan Stein from The Concern Foundation Laboratories at the Lautenberg Center for Immunology and Cancer Research (Jerusalem, Israel) for language editing.

\section{Funding}

This work was supported by the ISF-China program and by the ISF Moked grant. Further support came from the ICRF professorship grant, by the MOST-DKFZ grant, by the GIF grant. The study was also supported by the Israel Science Foundation (grant 502/15), the Kass Medical Research Award and the Israeli Society of Hematology and Transfusion Medicine research grant (to S.E).

\section{References}

1. Brinc D, Lazarus AH. Mechanisms of anti-D action in the prevention of hemolytic disease of the fetus and newborn. Hematology Am Soc Hematol Educ Program. 2009:185-191.

2. Lazarus AH, Crow AR. Mechanism of action of IVIG and anti-D in ITP. Transfus Apher Sci. 2003;28(3):249-255

3. Kumpel BM. On the immunologic basis of $\mathrm{Rh}$ immune globulin (anti-D) prophylaxis. Transfusion. 2006;46(9):1652-1656.

4. Kumpel BM. On the mechanism of tolerance to the $\mathrm{Rh} \mathrm{D}$ antigen mediated by passive anti-D (Rh D prophylaxis). Immunol Lett. 2002;82(1-2):67-73

5. Garratty G. The James Blundell Award Lecture 2007: do we really understand immune red cell destruction? Transfus Med. 2008;18(6):321-334.

6. Kumpel BM, Elson CJ. Mechanism of anti-Dmediated immune suppression--a paradox awaiting resolution? Trends Immunol. 2001;22(1):26-31.

7. Branch DR, Shabani F, Lund N, Denomme GA. Antenatal administration of Rh-immune globulin causes significant increases in the immunomodulatory cytokines transforming growth factor-beta and prostaglandin E2. Transfusion. 2006:46(8):1316-1322.

8. Bernardo L, Yu H, Amash A, Zimring JC, Lazarus AH. IgG-Mediated immune suppression to erythrocytes by polyclonal antibodies can occur in the absence of activating or inhibitory Fcgamma receptors in a full mouse model. J Immunol. 2015;195(5):2224-2230.
9. Spits H, Bernink JH, Lanier L. NK cells and type 1 innate lymphoid cells: partners in host defense. Nat Immunol. 2016;17(7):758-764.

10. Moretta A. Natural killer cells and dendritic cells: rendezvous in abused tissues. Nat Rev Immunol. 2002;2(12):957-964.

11. Bournazos S, Ravetch JV. Fcgamma receptor function and the design of vaccination strategies. Immunity. 2017;47(2):224-233

12. Fehniger TA, Cooper MA, Nuovo GJ, et al. CD56bright natural killer cells are present in human lymph nodes and are activated by $\mathrm{I}$ cell-derived IL-2: a potential new link between adaptive and innate immunity. Blood. 2003;101(8):3052-3057.

13. Yamin R, Lecker LS, Weisblum Y, et al. HCMV vCXCL1 binds several chemokine receptors and preferentially attracts neutrophils over NK cells by interacting with CXCR2. Cell Rep. 2016;15(7):1542-1553.

14. Amarilyo G, Verbovetski I, Atallah M, et al. iC3b-opsonized apoptotic cells mediate a distinct anti-inflammatory response and transcriptional NF-kappaB-dependent blockade. Eur J Immunol. 2010;40(3):699-709.

15. Alter G, Malenfant JM, Altfeld M. CD107a as a functional marker for the identification of natural killer cell activity. J Immunol Methods. 2004;294(1-2):15-22.

16. Iwamoto S, Omi T, Yamasaki M, Okuda H, Kawano M, Kajii E. Identification of 5 ' flanking sequence of RH50 gene and the core region for erythroid-specific expression. Biochem Biophys Res Commun. 1998; 243(1):233-240

17. Jiang N, Chen W, Jothikumar P, et al. Effects of anchor structure and glycosylation of Fcgamma receptor III on ligand binding affinity. Mol Biol Cell. 2016;27(22):3449-3458.

18. Koene HR, Kleijer M, Algra J, Roos D, von dem Borne AE, de Haas M. Fc gammaRIIIa$158 \mathrm{~V} / \mathrm{F}$ polymorphism influences the bind ing of IgG by natural killer cell Fc gammaRIIIa, independently of the $\mathrm{Fc}$ gammaRIIIa-48L/R/H phenotype. Blood. 1997;90(3):1109-1114

19. Irani V, Guy AJ, Andrew D, Beeson JG, Ramsland PA, Richards JS. Molecular properties of human IgG subclasses and their implications for designing therapeutic monoclonal antibodies against infectious diseases. Mol Immunol. 2015;67(2 Pt A):171-182.

20. Jennewein MF, Alter G. The immunoregulatory roles of antibody glycosylation. Trends Immunol. 2017;38(5):358-372

21. Seeling M, Bruckner C, Nimmerjahn F Differential antibody glycosylation in autoimmunity: sweet biomarker or modulator of disease activity? Nat Rev Rheumatol. 2017;13(10):621-630.

22. Ferlazzo G, Semino C, Melioli G. HLA class I molecule expression is up-regulated during maturation of dendritic cells, protecting them from natural killer cell-mediated lysis. Immunol Lett. 2001;76(1):37-41

23. Walzer T, Dalod M, Robbins SH, Zitvogel L, Vivier E. Natural-killer cells and dendritic cells: "l'union fait la force". Blood. 2005:106(7):2252-2258

24. Ferlazzo G, Tsang ML, Moretta L, Melioli G, Steinman RM, Munz C. Human dendritic cells activate resting natural killer (NK) cells 
and are recognized via the NKp30 receptor by activated NK cells. J Exp Med. 2002;195(3):343-351.

25. Miescher S, Zahn-Zabal M, De Jesus M, et al. $\mathrm{CHO}$ expression of a novel human recombinant IgG1 anti-RhD antibody isolated by phage display. $\mathrm{Br} \mathrm{J}$ Haematol. 2000;111(1):157-166

26. Kumpel BM, Goodrick MJ, Pamphilon DH, et al. Human $\mathrm{Rh} \mathrm{D}$ monoclonal antibodies (BRAD-3 and BRAD-5) cause accelerated clearance of $\mathrm{Rh} \mathrm{D}+$ red blood cells and suppression of Rh D immunization in Rh D-volunteers. Blood. 1995;86(5):1701-1709.

27. Miescher S, Spycher MO, Amstutz H, et al. A single recombinant anti- $\mathrm{RhD}$ IgG prevents $\mathrm{RhD}$ immunization: association of $\mathrm{RhD}$-positive red blood cell clearance rate with polymorphisms in the FcgammaRIIA and FcgammaIIIA genes. Blood. 2004;103(11): 4028-4035.

28. Beliard R, Waegemans T, Notelet D, et al. A human anti-D monoclonal antibody selected for enhanced FcgammaRIII engagement clears $\mathrm{RhD}+$ autologous red cells in human volunteers as efficiently as polyclonal anti-D antibodies. Br J Haematol. 2008;141(1):109-119.

29. Kapur R, Della Valle L, Sonneveld M, et al. Low anti-RhD IgG-Fc-fucosylation in pregnancy: a new variable predicting severity in haemolytic disease of the fetus and newborn. Br J Haematol. 2014;166(6):936-945.

30. Sulica A, Herberman RB. Cytophilic immunoglobulins revisited via natural killer cells. FASEB J. 1996;10(13):1495-1504.

31. Sulica A, Galatiuc C, Manciulea M, et al. Regulation of human natural cytotoxicity by IgG. IV. Association between binding of monomeric IgG to the Fc receptors on large granular lymphocytes and inhibition of natural killer (NK) cell activity. Cell Immunol. 1993;147(2):397-410.

32. Mandelboim O, Malik P, Davis DM, Jo CH Boyson JE, Strominger JL. Human CD16 as a lysis receptor mediating direct natural killer cell cytotoxicity. Proc Natl Acad Sci U S A.
1999.96(10):5640-5644

33. Terrell CE, Jordan MB. Perforin deficiency impairs a critical immunoregulatory loop involving murine CD8(+) T cells and dendritic cells. Blood. 2013;121(26):5184-5191.

34. Yang J, Huck SP, McHugh RS, Hermans IF, Ronchese F. Perforin-dependent elimination of dendritic cells regulates the expansion of antigen-specific CD8+ T cells in vivo. Proc Natl Acad Sci U S A. 2006;103(1):147-152

35. Manciulea M, Rabinowich H, Sulica A, et al Divergent phosphotyrosine signaling via FC gamma RIIIA on human NK cells. Cell Immunol. 1996;167(1):63-71.

36. Arora G, Hart GT, Manzella-Lapeira J, et al. NK cells inhibit Plasmodium falciparum growth in red blood cells via antibodydependent cellular cytotoxicity. Elife. 2018;7:e36806.

37. Urbaniak SJ. ADCC (K-cell) lysis of human erythrocytes sensitized with rhesus alloantibodies. II. Investigation into the mechanism of lysis. Br J Haematol. 1979;42(2):315-325. 